\title{
Effective Utilization of Transmission Line Capacity in a Meshed Network with Series Capacitor Upto its Thermal Limit
}

\author{
Ananda M. H, M. R. Shivakumar
}

\begin{abstract}
Power system networks are becoming interconnected for the purpose of power delivery to decrease the overall power generation cost. With insufficient control, the power systems become more complicated to function and less secure. The economics of $A C$ power transmission have always forced the planning engineers to transmit as much power as possible through a given transmission line. The smaller and thermally limited lines are crowded in many networks while other higher capacity lines run well below their thermal maximum. When series capacitors are introduced in the higher voltage cables, power may be transferred from the overloaded lines, maximizing the use of the existing line as well as complementing the performance of the power system. In this paper, a three-line meshed power system network with different thermal line limits is considered for the purpose of showing effective utilization of line network for maximum power flow through the intended line with series capacitor compensation. The simulations are performed by using PowerWorld simulator confirms the addition of series capacitor increases the power transfer through the line up to its thermal limit.
\end{abstract}

Keywords : Transmission interconnection, power flow, thermal limit, uprating transmission capacity, Series capacitor compensation.

\section{INTRODUCTION}

Rapid urbanization and industrialization put growing pressure on electric power utilities. Nearly all of the world's electrical supply systems are commonly interconnected extending to inter utility, inter regional and global links. This is done for to supply the fast-growing load, to improve reliability, to cut down the fuel cost and to reduce investment made on large power generators [1]. It could result in unwanted power flows, undue reactive power, dynamic swings in numerous parts of the system with insufficient control. Thus, it is not possible to use the complete potential of transmission interconnections.

So as to adapt to this issue new lines can be introduced. The excessively populated areas, limited forest coverage, the escalated utilization of land and growing refusal of new electrical lines, however, signify that there is a limited scope available for the existing electrical lines.
Revised Manuscript Received on March 5, 2020.

* Correspondence Author

Ananda M.H*, School of Electrical \& Electronics Engineering, REVA University/Research Scholar V.T.U, India. Email: anandmhdvg@ gmail.com M.R. Shivakumar, Sri Revana Siddeshwara Institute of Technology, V.T.U, India. Email: vatsa_mr@yahoo.com
This necessitates to transmit as much power as possible through a given transmission line and get rid of the need to build new lines. Up rating a transmission line can be very appealing relative to constructing a new line in aspects of having lower expenses and lower lead times [2].

A number of factors pose certain degree of limitation in order to allow the best utilization of the transmission asset and to enhance the loading capacity [3][4]. The power systems loading capability is constrained by:

- Current (thermal) constraints

- Voltage constraints

- Operating constraints

\section{THERMAL POWER FLOW LIMIT}

Typically, several lines with various voltage levels and thermal ratings are included in a power system. Uncompensated lines are restrained by way of their impedance in the measure of power they can transfer. For such lines, the concept of surge impedance loading is often regarded as an optimal loading point for the line since this load result in a uniform voltage profile along the line and no reactive power injected into either end of the line. However, the line's actual load may be both below and above the surge impedance load level. Figure 1 shows typical surge impedance load (SIL) limits for long high voltage power lines versus thermal load limits.

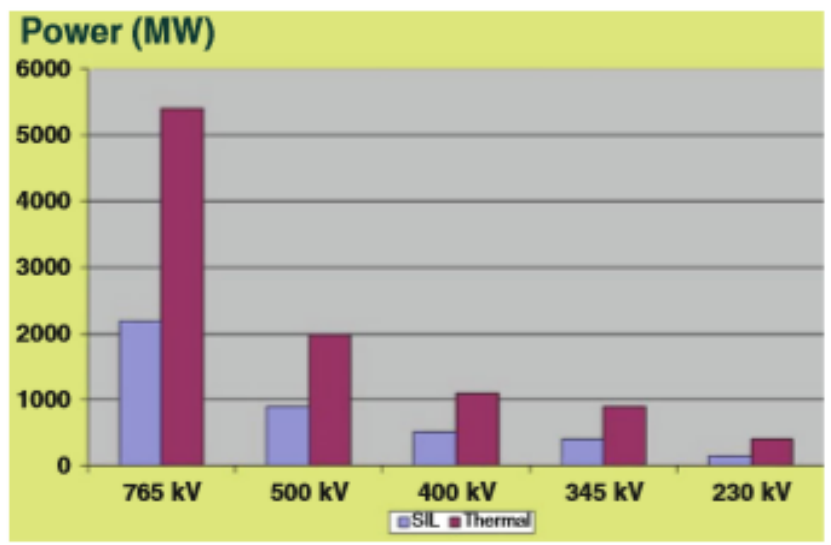

Fig. 1.Typical surge impedance load (SIL) limits without compensation versus thermal limits for long high voltage lines. Source: Reference [5, Fig.1]

Although the ratings in Figure 1 are typical, thermal limits rely upon the climate conditions and surrounding temperature. 
The overhead lines designed to restrain the temperature achieved by the energized conductors and the consequent sag and lack of tensile strength. Much of the time, the maximum temperature of conductor used in transmission lines signify ground clearance issues in preference to annealing of conductor.

Thermal power flow restrictions on overhead lines are designed to restrict the temperature of the energized conductors and the subsequent sag and reduction of tensile strength. As usually determined, thermal limit points are not a component of line length.

There are various potential techniques that can increase the thermal capacity of an existing line [6]. A few of the techniques utilized for thermal uprating of the transmission line are as below:

- Custom made conductors to suit specific applications (replacement by superconducting cables).

- Re-tensioning the existing conductors.

- Making sag adjustment.

- Tower reconfiguration;(Elevation of towers, Shifting of towers, putting of additional towers).

- Increasing conductor cross-section area.

- Performing Dynamic Thermal Rating Monitoring.

These techniques, however come at a cost and some are time consuming tasks. Therefore, strategies that enables line power to be increased near to its thermal limit safely and securely have been considered for better utilization of existing capacity lines.

\section{POWER FLOW OVER TRANSMISSION LINE}

Figure 2(a) illustrates a simplified case of power transmission over a line. Area 1 and area 2 may be any transmission substations associated through transmission line. $V_{1}$ and $V_{2}$ are the magnitude of bus voltages at these areas with an angle $\delta$ between the two.

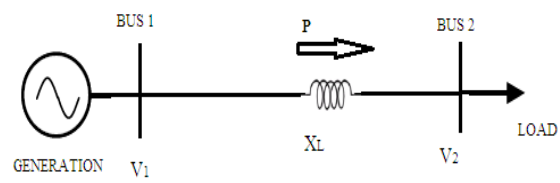

(a)

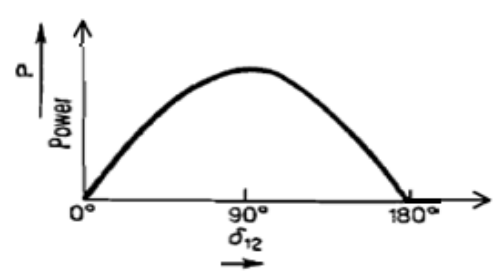

(b)

Fig. 2.Power flow over transmission line (a) Source to load power flow (b) Power angle curve.

Power flow through a lossless AC line is proportional to the voltages $\left(\mathrm{V}_{1}, \mathrm{~V}_{2}\right)$ at two ends of the line, the sine of the angle $(\delta)$ between the two-line ends and inversely proportional to the impedance between the end points of the line $\left(\mathrm{X}_{\mathrm{L}}\right)$ expressed as:

$$
P=\frac{V_{1} V_{2}}{X_{L}} \sin \delta
$$

As is well known, for long lines the impedance is large and the angle between the two ends of the line also becomes large if any significant power is to flow through the line. However, the active power flow over a transmission line also gives rise to reactive power.

$$
Q=\frac{V_{1} V_{2} \cos \delta-V_{2}^{2}}{X_{L}}
$$

That is, at a phase angle of 90 degrees, the active power transmission is maximum but the reactive power equals the active power. Figure 2(b) shows the half sine wave curve of active power increasing to a peak with an increase in $\delta$ from $0^{\circ}$ to $90^{\circ}$.

It is anything but difficult to suitable that without rapid control of the parameters $\mathrm{V}_{1}, \mathrm{~V}_{2}, \mathrm{~V}_{1}-\mathrm{V}_{2}, \mathrm{X}$ and $\delta$ the transmission line must be utilized to a level well underneath that relating to 90 degrees. This is essential to keep up a sufficient edge required for transient and dynamic stability and to guarantee that the system doesn't collapse following the blackout of the generator or a transmission line.

Increase and decrease of the value of $X$ will increase and decrease the height of the curves (i.e., varies the power flow) respectively as shown in Fig. 3.

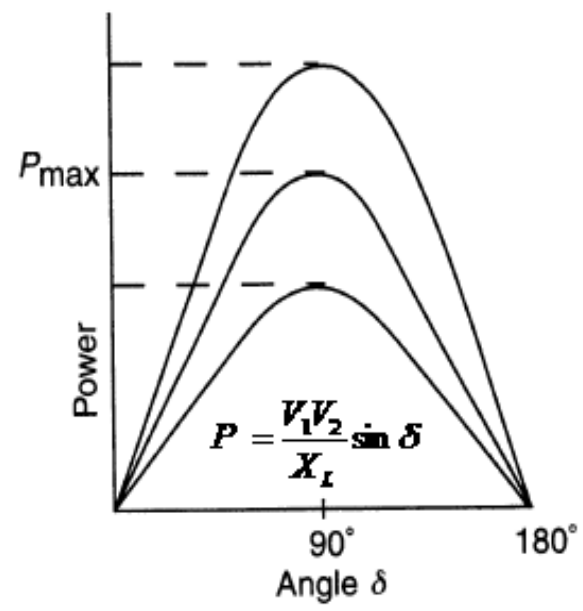

Fig. 3.Power angle curve for various values of $X$.

\section{SERIES CAPACITOR COMPENSATION}

Series capacitors were used to compensate for inductive reactance in transmission and distribution lines by canceling the line reactance to boost power transmission capacity. The amount of capacitive reactance inserted reduces the inductive reactance. Compensation implies modifying a transmission line's electrical attributes in an attempt to improve its power transmission ability, to meet the basic transmission requirements [7-11]. This can be clear by investigating the fundamental power flow equation for the system considered as shown in Fig. 4. 


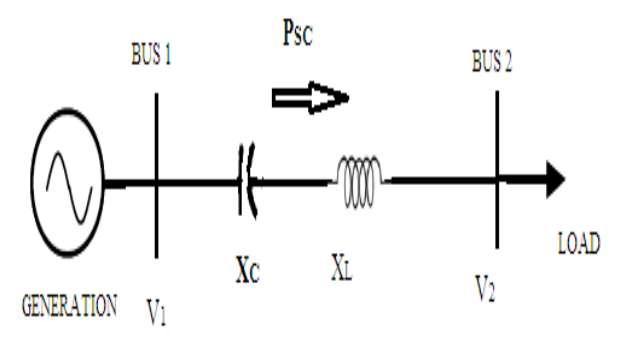

Fig. 4.Power flow through transmission line with series capacitor compensation.

The transmitted power in the system shown in Fig. 4 is indicated by

$$
P_{S C}=\frac{V_{1} V_{2}}{\left(X_{L}-X_{C}\right)} \sin \delta>\mathrm{P}
$$

Where $\mathrm{P}_{\mathrm{SC}}$ is active power transfer after series compensation $\mathrm{X}_{\mathrm{C}}$.

With the reactance of the inserted capacitive component, i.e. the series capacitor equivalent to $X_{C}$ and the line's inductive reactance equivalent to $\mathrm{X}_{\mathrm{L}}$, we can present a measure of the degree of series compensation $\mathrm{k}$.

$\mathrm{k}=\mathrm{X}_{\mathrm{C}} / \mathrm{X}_{\mathrm{L}}$

Usually, the degree of compensation k selected is in an order of $0.3 \leq \mathrm{k} \leq 0.7$ in power transmission operations and control[12].

Substituting $\mathrm{X}_{\mathrm{C}}$ by $\mathrm{k}$, we get

$P=\frac{V_{1} V_{2}}{X_{L}(1-k)} \sin \delta$

From (1) and (4) it is apparent that the active power flow could be improved by reducing the total series reactance of the line. $\mathrm{X}_{\mathrm{C}}$ decreases the total transfer impedance, thus enabling an enhanced power flow for the same system angle, or a decrease of the system angle, also improving the stability margins. If several lines are parallel or nearly parallel, then the power flow will be exchanged on them in relation to their respective admittances. If these lines have differing ratios of thermal capacity to series admittance then the flow exchange between them will not be in proportion to their thermal capacity. Consequently, as total flow increases, one line will reach its capacity before the others.

To summarize, power transmission circuits with series capacitor compensation allows numerous advantages:

- It improves the transmission of active power over the transmission system network without breaking the stability of the angle or voltage.

- It offers an economical means to meet the transmission system's reactive power demands.

- Increase loading ability of line up to its thermal capability.

- Allows a balanced power sharing between parallel lines to maximize the use of transmission line.

\section{POWER FLOW IN A MESHED LINE}

To demonstrate the effectiveness of series compensation, a simple three bus meshed power system network is considered as shown in Fig. 5. Table I provides the system details considered.

Two generators at different areas 1 and 3 are sending power to a load at area 2 through a meshed network consisting of three lines 1-3, 1-2 and 3-2. The corresponding PowerWorld simulator model for a meshed network is shown in Fig. 6.

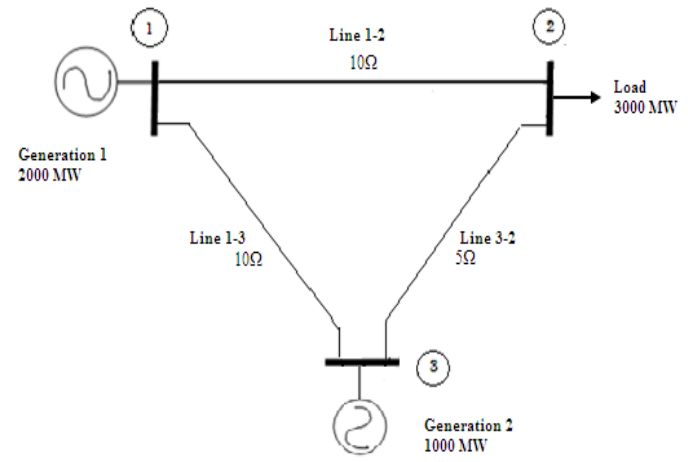

Fig. 5.Power system network considered.

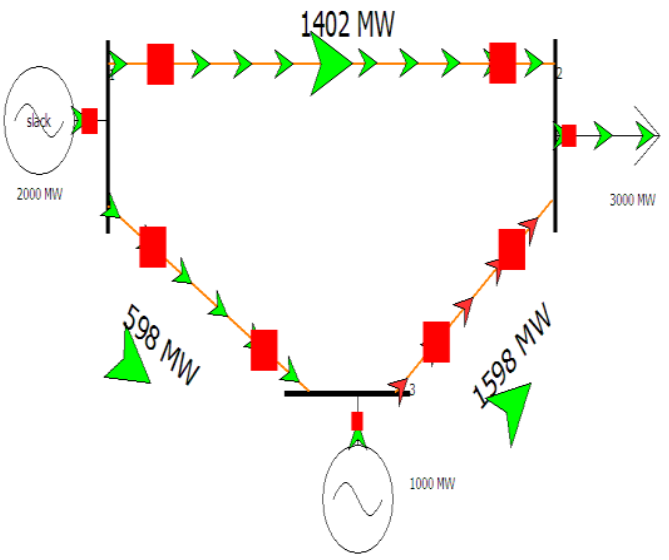

Fig. 6.PowerWorld simulator model considered for a meshed network without series capacitor compensation.

TABLE I. SYSTEM DATA BEFORE CAPACITOR COMPENSATION

\begin{tabular}{|c|c|c|c|}
\hline $\begin{array}{c}\text { Transmission } \\
\text { Line }\end{array}$ & $\begin{array}{c}\text { Total line } \\
\text { impedance }\end{array}$ & $\begin{array}{c}\text { Thermal limit / } \\
\text { Continuous } \\
\text { rating of } \\
\text { transmission } \\
\text { line }\end{array}$ & $\begin{array}{c}\text { Power flow } \\
\text { through } \\
\text { transmission line } \\
\text { (Before capacitor } \\
\text { compensation) }\end{array}$ \\
\hline Line 1-2 & $10 \Omega$ & $2000 \mathrm{MW}$ & $1402 \mathrm{MW}$ \\
\hline Line 1-3 & $10 \Omega$ & $1000 \mathrm{MW}$ & $598 \mathrm{MW}$ \\
\hline Line 3-2 & $5 \Omega$ & $1250 \mathrm{MW}$ & $1598 \mathrm{MW}$ \\
\hline
\end{tabular}

An aggregate load of $3000 \mathrm{MW}$ would be supplied to the load at area 2 from one of the generators at area 1 generating 2000 MW and the other generator at area 3 is generating 1000 MW. Such a circumstance would overload the line 3-2 (charged at $1598 \mathrm{MW}$ for its thermal limit of $1250 \mathrm{MW}$ ) thus power generation at area 3 needs to be reduced and raised at area 1 to satisfy the load demand to reduce the loading of line 3-2.

To overcome this constraint, we consider including a modest amount of series 
capacitive reactance $\mathrm{Xc}$ to an uncompensated line under the supposition that prior to compensation the power flows are as specified in Table I. Figure 6 shows the arrangement of considered network with the insertion of Xc in line 1-2.

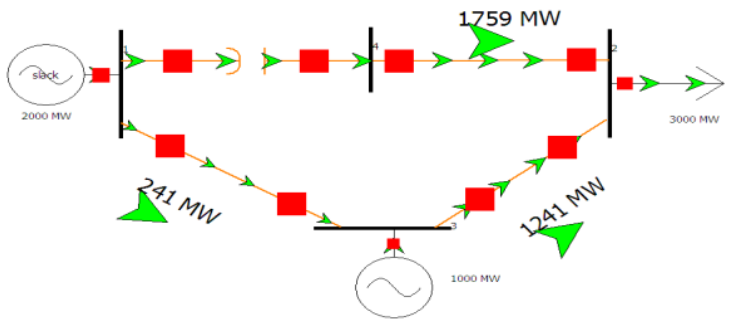

Fig. 7.PowerWorld simulator model considered for a meshed network with series capacitor compensation.

For various values of degree of series capacitor compensation, the simulation result values obtained from fig.8.

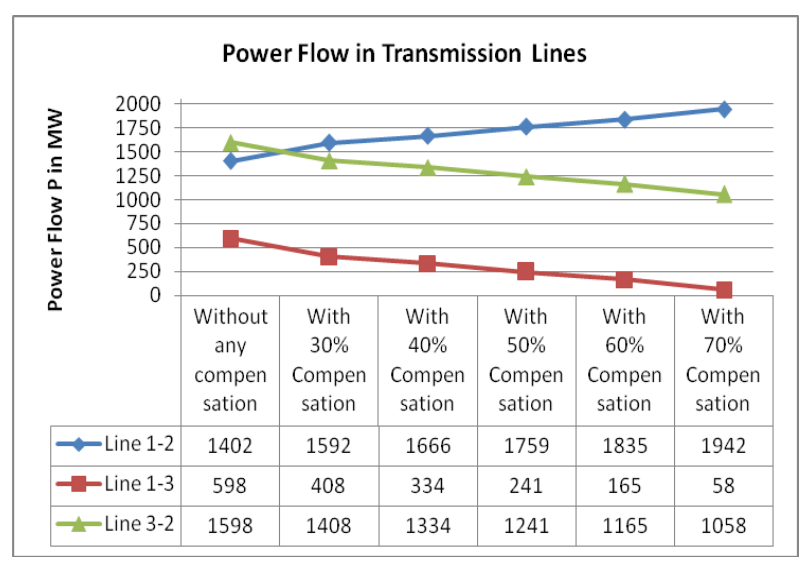

Fig..8.System Data After Capacitor Compensation

\section{RESULT AND DISCUSSION}

The study performed is specially focused on achieving the objective of increasing the power system loading capacity of a transmission line with the thermal limit as its constraint. Simulation results obtained from the PowerWorld simulator are tabulated in TABLE I and TABLE II. It is clear from the results obtained that, if a series capacitor with $50 \%$ compensation is inserted in line 1-2 results in increasing the power transfer capability to $1759 \mathrm{MW}$ within its thermal limit and also the line 3-2 overloading has been reduced to 1241 MW from its overloaded value of $1598 \mathrm{MW}$.

Increased compensation requires higher Mvar capacity of capacitor and increased cost. Typical series capacitor applications are with the range of $30 \%$ to $70 \%$ compensation. There are other factors that may place limits on the compensation level, such as subharmonic stability, sub synchronous resonance and switching transients.

If the series capacitance inserted is adjustable, the power flow control can be achieved according to the thermal limits and generation availability. The most straightforward application involves thyristor switching of elements such as capacitors. Normally, Thyristor controlled components are more costly than their equivalents with mechanical switches. Standard FACTS facilities include a mix of mechanically and electronically controlled components due to cost consideration. Table III summarizes the effective cost of uprating transmission capacity for new transmission line and series capacitor compensation. It should be stressed that these estimates are rough and that they may not be completely practically identical.

TABLE II. EFFECTIVE COSTS OF NEW CAPACITY AND FOR UPRATING TRANSMISSION CAPACITY FOR SERIES COMPENSATION. ALL COSTS ARE IN CIRCA 2005 U.S DOLLARS. SOURCE: DATA IS EXCERTED FROM[2, TABLE III]

\begin{tabular}{|c|c|c|c|c|}
\hline Type & Technology & $\begin{array}{l}\text { Specific } \\
\text { Cost }\end{array}$ & $\begin{array}{l}\text { Assumptions for } \\
\text { effective cost } \\
\text { calculation, base } \\
\text { case operation }\end{array}$ & $\begin{array}{c}\text { Effectiv } \\
\text { e Cost } \\
\text { (\$/MW- } \\
\text { mile) }\end{array}$ \\
\hline $\begin{array}{l}\text { New } \\
\text { Capacity }\end{array}$ & $\begin{array}{l}\text { New } \\
\text { transmission } \\
\text { line }\end{array}$ & $\begin{array}{l}\$ 400 / \mathrm{MW}- \\
\text { mile to } \\
\$ 1000 / \mathrm{MW} \\
\text {-mile }\end{array}$ & $\begin{array}{l}\text { Above } 200 \mathrm{kV} \\
\text { operation }\end{array}$ & $\begin{array}{l}400-100 \\
0\end{array}$ \\
\hline \multirow{2}{*}{$\begin{array}{l}\text { Increased } \\
\text { Utilization }\end{array}$} & $\begin{array}{l}\text { Series } \\
\text { capacitive } \\
\text { compensatio } \\
\mathrm{n}(\text { Switched })\end{array}$ & $\begin{array}{l}\$ 15 / \mathrm{kVAr} \\
\text { to } \\
\$ 60 / \mathrm{kVAr}\end{array}$ & $\begin{array}{l}345 \mathrm{kV} \text { line } \\
\text { operated at half } \\
\text { thermal capacity, } \\
\text { 100-mile length }\end{array}$ & $45-180$ \\
\hline & $\begin{array}{l}\text { Series } \\
\text { capacitive } \\
\text { compensatio } \\
\mathrm{n}(\mathrm{FACTS}) \\
\end{array}$ & $\begin{array}{l}\$ 20 / \mathrm{kVAr} \\
\text { to } \\
\$ 60 / \mathrm{kVAr}\end{array}$ & $\begin{array}{l}345 \mathrm{kV} \text { line } \\
\text { operated at half } \\
\text { thermal capacity, } \\
\text { 100-mile length }\end{array}$ & $60-360$ \\
\hline \multirow{2}{*}{$\begin{array}{l}\text { Increased } \\
\text { thermal } \\
\text { capacity }\end{array}$} & $\begin{array}{l}\text { Re-condition } \\
\text { ing with } \\
\text { ACCC cable }\end{array}$ & $\$ 5 /$ foot & $\begin{array}{l}\$ 0-200 \mathrm{k} \\
\text { additional costs } \\
\text { per } \quad \text { mile, } \\
\text { doubling } 345 \mathrm{kV} \\
\text { thermal capacity }\end{array}$ & $130-300$ \\
\hline & $\begin{array}{l}\text { Line } \\
\text { tensioning } \\
\text { devices }\end{array}$ & $\begin{array}{l}\$ 10,000 \text { per } \\
\text { tensioning } \\
\text { device }\end{array}$ & $\begin{array}{l}345 \mathrm{kV} \text { line, } \\
\text { average } 0.2-0.5 \\
\text { devices per span, } \\
6 \text { spans per mile }\end{array}$ & $70-170$ \\
\hline
\end{tabular}

As noticed typical new transmission line costs in the range of $\$ 400 / \mathrm{MW}$-mile to $\$ 1000 / \mathrm{MW}$-mile for transmission line operating above $200 \mathrm{kV}$. Comparing updating costs with new building costs, we find that: upgrading costs for series capacitive compensation are surely below the range of new transmission line costs.

\section{CONCLUSION}

In this paper for the objective of showing the line loading ability of the transmission system by the insertion of series capacitor was studied. The simulation results obtained from the Power World simulator demonstrate the addition of a series capacitor to the network will significantly boost power flow through the intended line considering its thermal limit. Boosting extra power out of existing lines can get rid of the need to build new lines that will add to reduced environmental effect and significant cost and time saving.

\section{REFERENCES}

1. N.G. Hingorani and L. Gyugyi., "Understanding FACTS-Concepts and Technology of Flexible AC Transmission Systems", IEEE Press, Newyork, 2000.

2. R. Baldick and R. P. O'Neill, "Estimates of Comparative Costs for Uprating Transmission Capacity," in IEEE Transactions on Power Delivery, vol. 24, no. 2, pp. 961-969, April 2009.

3. Prabha Kundur, "Power System Stability and Control", Tata McGrawHill, 2008.

4. R. Grunbaum and J. Samuelsson, "Series capacitors facilitate long distance AC power transmission," 2005 IEEE Russia Power Tech, St. Petersburg, 2005, pp. 1-6.

Stig Nilsson, Antonio Ricardo de Mattos Tenório, Subir Sen, Andrew Taylor, Shukai Xu, Gang Zhao, Qiang Song, Bo Lei. "Chapter 9-1 Application Examples of the Thyristor Controlled Series Capacitor," Springer Science and Business Media LLC, 2019. 
5. Jose R. Daconti and Daniel c. Lawry "Increasing Power Transfer Capability of Existing Transmission Line," Published in Transmission and Distribution Conference and Exposition, (2003 IEEE).

6. R. Gruenbaum, J. Rasmussen and C. Li, "Series capacitors for increased power transmission capability of a $500 \mathrm{kV}$ grid intertie," 2012 IEEE Electrical Power and Energy Conference, London, ON, 2012, pp. 164-169.

7. R.N. Nayak, Y.K. Sehgal and Subir Sen, "Series Compensation on 400kV Transmission Line- A Few Design Aspects," National Power Systems Conference, NPSC 2004.

8. Timothy J.E. Miller., "Reactive Power Control in Electric Systems," Wiley India, 2010

9. L.E. Bock and G.R. Mitchell, "Higher Line Loadings with Series Capacitors," Transmission, March 1973.

10. I.B. Johnson, "Capacitor Banks for Transmission System Compensation,” Missouri Valley Electr. Assoc., April 1973.

11. R. Grünbaum, G. Ingeström, B. Ekehov and R. Marais, "765 kV series capacitors for increasing power transmission capacity to the Cape Region," IEEE Power and Energy Society Conference and Exposition in Africa: Intelligent Grid Integration of Renewable Energy Resources (PowerAfrica), Johannesburg, 2012, pp. 1-8.

\section{AUTHORS PROFILE}

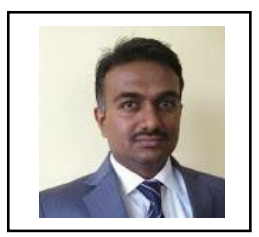

Ananda M.H, Assistant Professor, School of Electrical and Electronics Engineering, REVA University, holds his B.E in Electrical \& Electronics Engineering and M.Tech in Power Systems \& Power Electronics. His employment experience includes 6 years of industry experience from ABB Ltd., DM-Power Electronics and 7 years of teaching experience. He is Member of IAENG (International Association of Engineers), Member of IEI (Institution of Engineers India) and student member of IEEE. His special fields of interest included FACTS devices and their application to the power system, FOCS, Smart Grid, Micro Grid, Battery charging technology, Grid integration of renewable energy sources.

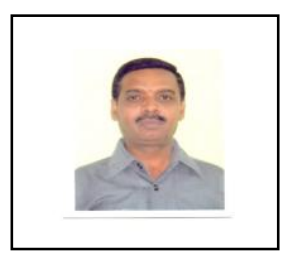

Dr. M.R. Shivakumar, Professor and Principal Sri Revana Siddeshwara Institute of Technology Bangalore is an Electrical power Engineering graduate from University of Mysore. Post graduate from Bangalore University and also a $\mathrm{PhD}$ holder in Electrical Engineering (Power Systems) from the same university. He has more than Three decades of teaching experience and guided the students for their Post graduate as well as doctorate degrees. He is a life member of The Indian Society for Technical Education, A Fellow of The Institution of Engineers (India), A member of Institution of Engineering and Technology MIET (UK). His field of interest includes power system stability, FACTS controllers, power electronics applications. 